\title{
Autonomous Energy Harvesting and Prevention of Cell Reversal in MFC Stacks
}

\author{
George Papaharalabos, ${ }^{\text {a,z }}$ Andrew Stinchcombe, ${ }^{\text {a }}$ Ian Horsfield, ${ }^{\text {a }}$ Chris Melhuish, ${ }^{\text {a }}$ \\ John Greenman, ${ }^{\mathbf{b}}$ and Ioannis Ieropoulos ${ }^{\mathrm{a}, \mathrm{z}}$ \\ ${ }^{a}$ Bristol BioEnergy Centre, Bristol Robotics Laboratory, University of the West of England, Bristol BS16 1QY, \\ United Kingdom \\ ${ }^{b}$ Faculty of Applied Sciences, University of the West of England, Bristol, United Kingdom
}

\begin{abstract}
This study presents a novel method for avoiding cell reversal whilst optimising energy harvesting from stacked Microbial Fue Cells (MFCs) by dynamically reconfiguring the electrical connections between them. The sequential changing of in-parallel and in-series electrical connections in an 8-MFC stack resulted in energy being transferred twice as fast into a super-capacitor avoiding cell reversal in MFCs as opposed to a fixed in-series configuration. This approach, allows for a lower internal resistance state within the stack compared to a fixed electrical configuration. This is critical in the initial stages of energy extraction from MFCs connected electrically in-series where the impedance of the capacitor is drawing high levels of current and cell reversals are likely to occur and hinder performance. Automation of electrical connections doubled the extracted power from the stack whilst halving the charging times without any cell reversal occurrence. The electrical reconfiguring of MFCs was performed by a USB-powered switch-box that modulated the stack's connections. This lead to the development of an energy autonomous switch-box circuitry powered solely by the MFC stack with negligible impact on the overall energy harvesting efficiency (i.e. above $90 \%$ ).

(c) The Author(s) 2016. Published by ECS. This is an open access article distributed under the terms of the Creative Commons Attribution 4.0 License (CC BY, http://creativecommons.org/licenses/by/4.0/), which permits unrestricted reuse of the work in any medium, provided the original work is properly cited. [DOI: 10.1149/2.0081703jes] All rights reserved.

(c) BY
\end{abstract}

Manuscript submitted September 21, 2016; revised manuscript received November 18, 2016. Published December 8, 2016. This paper is part of the JES Focus Issue on Biological Fuel Cells.

Microbial fuel cells (MFCs) are bio-electrochemical systems comprising bacteria in the anode that convert organic matter into electricity. Stacking MFC units can increase the voltage and current output so as to meet the demands of most commercial electronic devices and allow further energising of complex and energy intensive circuitries. ${ }^{1-6}$ Nevertheless, a MFC responds to sudden chemical and biochemical changes such as substrate diffusion and concentration, $\mathrm{pH}$, temperature, presence of oxygen, biofilm community structure, biofilm thickness and density. ${ }^{7-11}$ These factors can affect microbial communities and the overall redox potential in the anode which can further result in polarity reversals, a frequently observed phenomenon known to impede stacked MFCs. Reverse of polarity usually happens in an MFC when its internal resistance $\left(R_{\text {int }}\right)$ increases rapidly ${ }^{6,12,13}$ and many studies have focused on explaining and predicting this phenomenon. ${ }^{6,14-16}$ As a result, the least performing -reversed- MFC in a stack can cause large variations on the overall performance and efficiency. ${ }^{1}$ To date, reports suggest that this sudden change in $\mathrm{R}_{\text {int }}$ is triggered either by $a$ ) substrate depletion in the anode, ${ }^{14,15} b$ ) a "heavy" external load - low $\mathrm{R}_{\text {ext }}$ - connected to the stack that draws current at levels higher than the anodophillic biofilm can deliver, ${ }^{1,17,18}$ or $c$ ) it is a case of slow kinetics in the anode or the cathode. ${ }^{16,19}$

Research groups have attempted to develop power management systems (PMS) for tackling the issue. ${ }^{20-22}$ In 2011, Pinto et al. ${ }^{22}$ suggested that a maximum power point (MPP) matching algorithm could possibly prevent MFCs operating at values below the $\mathrm{R}_{\text {int }}$ hence avoiding reversal. It was not until 2014 that Boghani et al. ${ }^{20}$ developed a USB powered MPP matching PMS capable of preventing cell reversal in serially stacked MFCs whilst maximising energy harvesting. That was achieved by monitoring the voltage continuously whilst applying a dynamic resistance MPP matching to each cell in the stack. The tracking algorithm of this PMS would automatically adjust the $\mathrm{R}_{\mathrm{ext}}$ to the $\mathrm{R}_{\text {int }}$ at any given moment thus not allowing a MFC with low voltage levels to undergo into negative potential because the algorithm would increase the $\mathrm{R}_{\mathrm{ext}}$. A different approach was attempted by Kim et $a{ }^{21}$ whereby a capacitor-based system was used to increase the overall voltage from a MFC stack (in-parallel configured) by charging a group of capacitors in-parallel and then discharging in a series manner. This was one of the first attempts to boost the voltage without the use of DC-DC converters but every charging/discharging cycle utilized only $50 \%$ of the available energy stored due to capacitor-tocapacitor charge transfer physical limitations.

Based on previous findings, dynamic reconfiguration of electrical connections in a MFC stack allowed for decreased charging times of a super-capacitor by gradually switching from in-parallel to serial connections of stacked units. ${ }^{23}$ Moreover, this major improvement in performance seemed to be related to cell reversals prolepsis. As such, the present study illustrates the feasibility of an automated switching circuitry for simultaneous energy optimization and cell reversal prevention, by dynamically combining a range of all physical electrical connections within a stack.

\section{Experimental}

MFC stack construction and operation.-Eight single chamber MFCs with an anodic volume of $6.25 \mathrm{~mL}$ each, were 3D printed using RC25 Nanocure resin. ${ }^{2}$ Each anode consisted of a $155 \mathrm{~cm}^{2}$ untreated carbon fiber veil electrode, folded 5-times to form a cuboid and had an ion exchange membrane (IEM, CMI, Membranes International, USA) as a separator. Open-to-air cathode electrodes consisted of carbon cloth with a s.a (surface area) of $6 \mathrm{~cm}^{2}$, with a layer of activated carbon (AC) particles $\left(60 \pm 2 \mathrm{mg} / \mathrm{cm}^{2}\right)$ and PTFE (20\% wt) mixture as previously described. ${ }^{24}$ For this study, the AC and PTFE mixture was hot pressed $\left(200^{\circ} \mathrm{C}\right.$ and $\left.300 \mathrm{psi}\right)$ on the carbon cloth. Activated sewage sludge (Wessex Water Scientific Laboratory, Saltford, UK) was used as the inoculum and feedstock $(\mathrm{pH}$ 6.9) for a period of two weeks. During this period, each MFC was connected to a fixed $1 \mathrm{k} \Omega$ resistive load. This value was chosen based on impedance matching experiments from the same type of MFC, as used in a previous study. ${ }^{25}$ Following this period, the feedstock was replaced with neat human urine and MFCs were fed $5 \mathrm{~mL}$ every 24 hours for the duration of the experiments; all MFCs were operated in fed-batch mode under controlled ambient temperature conditions $\left(22 \pm 1^{\circ} \mathrm{C}\right)$.

Data logging and processing.-Voltage in millivolts was recorded every 1 second intervals using the switch converter's (see MFC stack digital switch converter section) and logged via the LabVIEW interface used for switching control and automation. Current was measured 


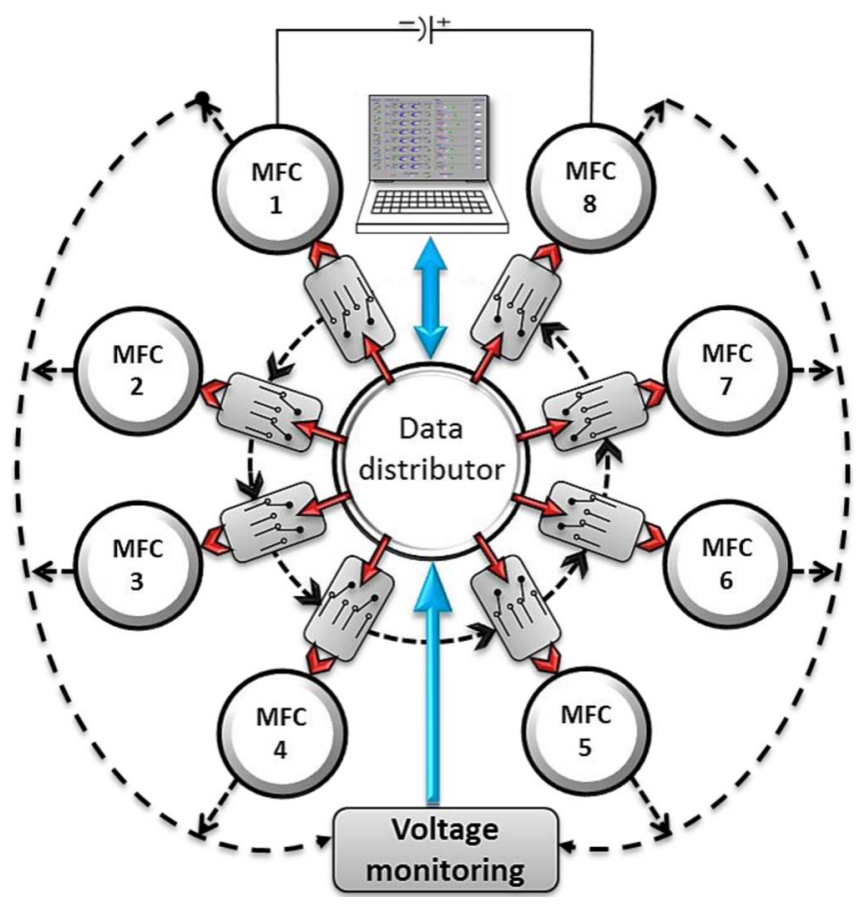

Figure 1. Schematic of the digital switch converter operation.

every 1 second with a TENMA 72-1016 bench multimeter. Polarization runs data were logged either with the use of a Resistorstat ${ }^{26}$ or with the use of a manual variable resistor for open-circuit voltage $(\mathrm{OCV})$ values exceeding $2.5 \mathrm{~V}$, using the same range of resistance values and time intervals. Data processing was performed with GraphPad Prism version 5.01 (GraphPad, San Diego). Power $\left(\mathrm{P}_{\mathrm{D}}\right)$ and current density $\left(\mathrm{C}_{\mathrm{D}}\right)$ were normalized using the cathode s.a $\left(6 \mathrm{~cm}^{2}\right)$ and volumetric $\mathrm{P}_{\mathrm{D}}$ was calculated based on the overall reactor volume $(6.25 \mathrm{~mL})$. The cathode was used as a means of normalization based on a previous study where the performance of this type of MFC was greatly affected by the cathodic oxygen reduction reactions. ${ }^{25}$ The internal resistance was calculated based using the textbook Physics technique, which is based on Ohm's and Kirchoff's law's and Jacobi's maximum power transfer theorem $\left[\mathrm{R}_{\mathrm{int}}=\left(\mathrm{V}_{\mathrm{OC}} / \mathrm{I}\right)-\mathrm{R}_{\mathrm{L}}\right]$.

MFC stack digital switch converter.-For configuring the electrical connections within the MFC stack, a digital 8-channel switchbox without any boosting or harvesting circuitry was developed (Fig. 1). The hardware comprises a main data distribution controller (PIC32, Microchip. Inc, USA) connected to eight microcontrollers (PIC24) each assigned to a MFC. Each microcontroller operates four latching relays (double pole/double throw), which facilitates series/parallel reconfiguration with adjacent MFCs and also individual external load connection via differential channels. The time required for switching the position of a relay is estimated to be $10 \mathrm{~ms}$. A built-in 24-bit 8channel differential chip monitors individual MFC voltage levels and sends the data to the main controller, which interfaces via USB to a desktop computer, which also powers the switchbox (see supplementary material, Fig. S1). Customized software enables the control of each microcontroller and relay separately based on the user data input. The energy extracted from the stack is stored in a super-capacitor (1 Farad), which is charged up to $3 \mathrm{~V}$, resulting in a corresponding energy transfer of 4.5 Joules (or electric charge of 3 Coulombs). The automated switching box was extensively tested for accuracy and robustness for over a 12-month period of charging and discharging cycles. The mean calculations from the pentaplicates $(n=5)$ were each chosen from within this 12-month period in order to find discrepancies in the charging times or ever spot cell-reversals.

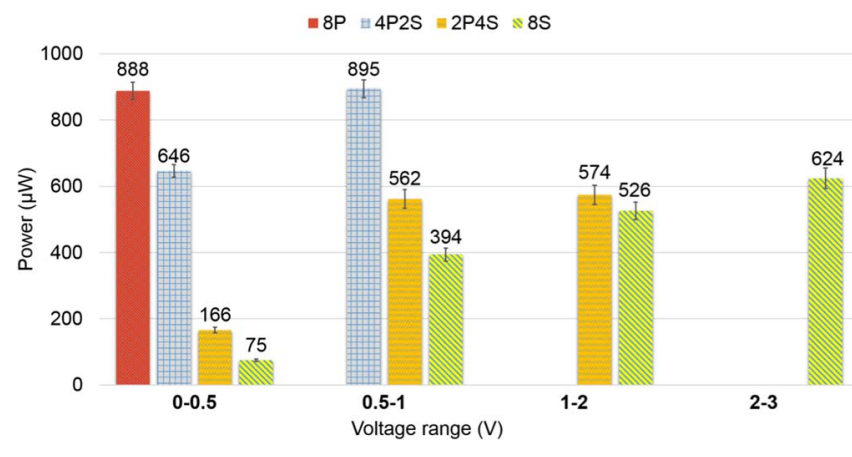

Figure 2. Calibration data of average power produced from all available configurations within specific voltage ranges during supercapacitor charging.

Selection of electrical configurations and switching intervals.Based on the number of MFCs, four different electrical configurations were investigated; i) 8 MFCs in-parallel (8P), ii) 4 MFCs connected in-parallel and the 2 resulting groups in-series (4P2S), iii) 2 MFCs inparallel and the 4 resulting pairs in-series (2P4S) and iv) all 8 MFCs inseries (8S). The increasing number of in-series electrically connected units allowed for higher OCVs. Additionally, each electrical setup was separately used to charge the super-capacitor until it reached the equivalent value of the configuration's OCV. The charging process was repeatedly tested for consistency and accuracy $(n=5)$. The current measured from each configuration, allowed for calculation of the average power within each voltage range (Fig. 2). As such, the highest power outputs at specific voltage spectra were selected to program the switch converter's software to change the configuration based on the following order; $8 \mathrm{P} \rightarrow 4 \mathrm{P} 2 \mathrm{~S} \rightarrow 2 \mathrm{P} 4 \mathrm{~S} \rightarrow 8 \mathrm{~S}$.

\section{Results and Discussion}

Performance of individual and stacked MFCs $(n=8)$.- Power and current outputs from the 8 MFCs ranged between $72-147 \mu \mathrm{W}$ and 226-370 $\mu \mathrm{A}$ (Fig. 3) respectively; these were equivalent to $P_{D}$ and $C_{D}$ values of $120-245 \mathrm{~mW} / \mathrm{m}^{2}$ and $426-616 \mathrm{~mA} / \mathrm{m}^{2}$. Results demonstrated differences between MFCs even though all units were maintained in a uniform manner. ${ }^{27}$ It is common in the literature to find discrepancies in similarly treated MFCs, whereby the feedstock and the concentration is similar but the biofilm formation is different due to dissimilar anode potentials. ${ }^{28-30}$

Performance readings from MFCs configured in four different electrical configurations were expected to be comparable to the $P_{D}$ of a single MFC $^{1}$ (Table I). However, studies using different experimental MFC setups have shown that stacking with various electrical configurations, exhibited dissimilar $\mathrm{P}_{\mathrm{D}}$ and $\mathrm{C}_{\mathrm{D}}$, where some configurations produced higher values than those from single MFCs. ${ }^{12,13}$ According to conventional circuit theory, the overall resistance in a parallel connection always tends to the lowest individual value. Based on the higher number of parallel elements in both the $8 \mathrm{P}$ and $4 \mathrm{P} 2 \mathrm{~S}$ configurations, it can be suggested that the improvement in performance was related to the consequent decrease of the collective $R_{\text {int }}$ that allowed for $P_{D}$ and $C_{D}$ similar to the best performing MFC $4\left(245 \mathrm{~mW} / \mathrm{m}^{2}\right.$ and $616 \mathrm{~mA} / \mathrm{m}^{2}$ ). This proposed that the individual power characteristics and the resultant theoretical projection from a group of MFCs may not always be representative of their real power capability. ${ }^{12}$ The high number of in-series elements along with the decrease in performance in both the $2 \mathrm{P} 4 \mathrm{~S}$ and $8 \mathrm{~S}$ seemed to be related with the resistance values at certain points in the polarization runs -cell reversals- that limited the stack from reaching at least the densities of a single unit (data not shown).

Polarity reversal during charging in a series configuration.-It is often observed in serially stacked batteries that a weak cell can cause an imbalance when high energy outputs are required. ${ }^{31}$ Weaker cells may not reverse immediately but will decrease in voltage quicker 


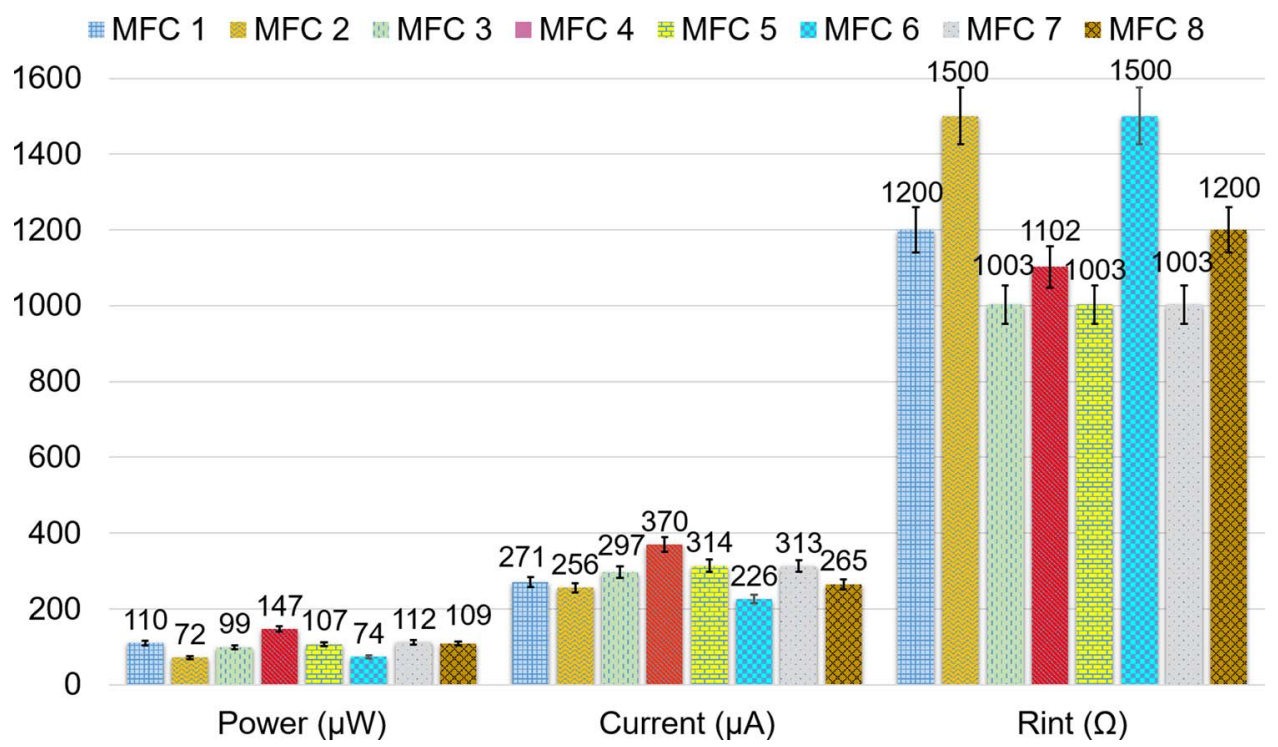

Figure 3. Performance of individual MFC units.

\begin{tabular}{|c|c|c|c|c|c|}
\hline MFC status & Power $\mu \mathrm{W}\left(\mathrm{mW} / \mathrm{m}^{2}\right)\left(\mathrm{W} / \mathrm{m}^{3}\right)$ & Current $\mu \mathrm{A}\left(\mathrm{mA} / \mathrm{m}^{2}\right)\left(\mathrm{A} / \mathrm{m}^{3}\right)$ & $\mathrm{R}_{\text {int }} \Omega$ & $\mathrm{OCV}(\mathrm{V})$ & Voltage in MPPT (V) \\
\hline MFC unit* & $103(173)(17)$ & $289(481)(46)$ & 1188 & 0.62 & 0.32 \\
\hline $8 \mathrm{P}$ & $1243(258)(25)$ & 3427 (714) (68) & 105 & 0.57 & 0.36 \\
\hline $4 \mathrm{P} 2 \mathrm{~S}$ & 1146 (238) (23) & 2361 (492) (47) & 205 & 1.36 & 0.48 \\
\hline $2 \mathrm{P} 4 \mathrm{~S}$ & 692 (144) (14) & $826(172)(16)$ & 1003 & 1.52 & 0.82 \\
\hline $8 \mathrm{~S}$ & $686(143)(13.7)$ & $294(62)(6)$ & 8000 & 3.92 & 2.35 \\
\hline
\end{tabular}

${ }^{*}$ Mean power derived from 8 units.

than the stronger ones under a low external load. In a similar manner, because of the variance in power, current and $R_{\text {int }}$ amongst the 8 MFCs, forward and backward polarizations ${ }^{1}$ were performed in the $8 \mathrm{~S}$ configuration in order to identify weak units that could possibly go into reversal (Fig. 4). In the forward polarization the individual monitoring showed that five MFCs reversed in polarity across the $6 \mathrm{k} \Omega-3 \Omega$ range. Similarly, the backward polarization recorded four MFCs with a negative potential within the range of $3 \Omega-6 \mathrm{k} \Omega$. After this point, all MFCs recovered to positive values as the external resistance value was increasing. In both cases the $6 \mathrm{k} \Omega$ was the resistance value just before or after the MPP $-8 \mathrm{k} \Omega$ - with the highest current from both the $8 \mathrm{~S}$ and 2P4S. MFCs 5, 6 and 7 reversed in polarity in both polarization scans with MFC 6 having the highest $\mathrm{R}_{\text {int }}(1500 \Omega)$. However, the rest of the MFCs that underwent reversal were different in each polarization with a $R_{\text {int }}$ either $1003 \Omega$ or $1200 \Omega$. The discrepancies from different units when performing the forward and backward polarizations, suggested that voltage reversal led to a 'cascading effect' in the stack and affected even well-performing MFCs with low $\mathrm{R}_{\text {int }}$ and overall high power. ${ }^{32}$

PMS efficacy vs $8 \mathrm{~S}$ configuration.-The OCV from the $8 \mathrm{MFCs}$ in-series was $4.2 \mathrm{~V}$ and it took approximately 3 hours (184 $\pm 3 \mathrm{~min})$ to charge the super-capacitor from $0-3 \mathrm{~V}$. Detailed voltage monitoring of the MFCs charging the super-capacitor revealed that during the first 60 minutes four MFCs went into reversal (Fig. 5A). Cell reversals that occurred in the $8 \mathrm{~S}$ stack whilst charging the super-capacitor compared to the same configuration during the backward polarisation showed that the reversed MFCs were different to the units that changed polarity in the backward polarization. It was also observed that the same MFCs that reversed during the charging process reversed also in the forward polarization. That being the case, it has previously been suggested that cell reversal propagation in a serially connected stack could be predicted based on the OCV and the $\mathrm{R}_{\text {int }}$ of individual

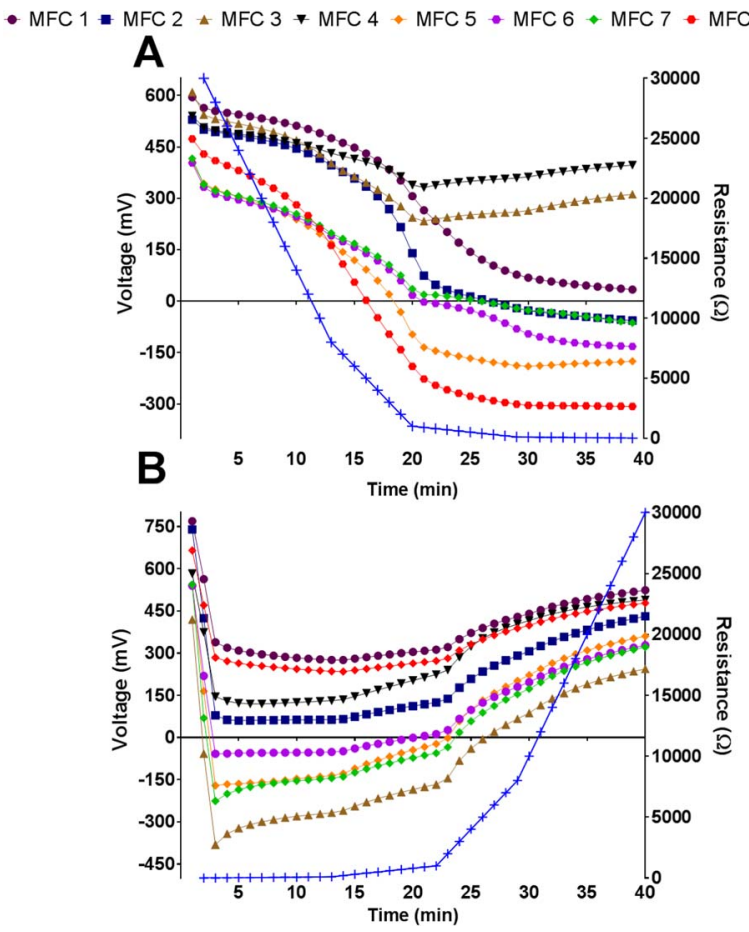

Figure 4. Voltage monitoring on each unit from forward (A) and reverse (B) polarizations when all $8 \mathrm{MFCs}$ are in-series. 


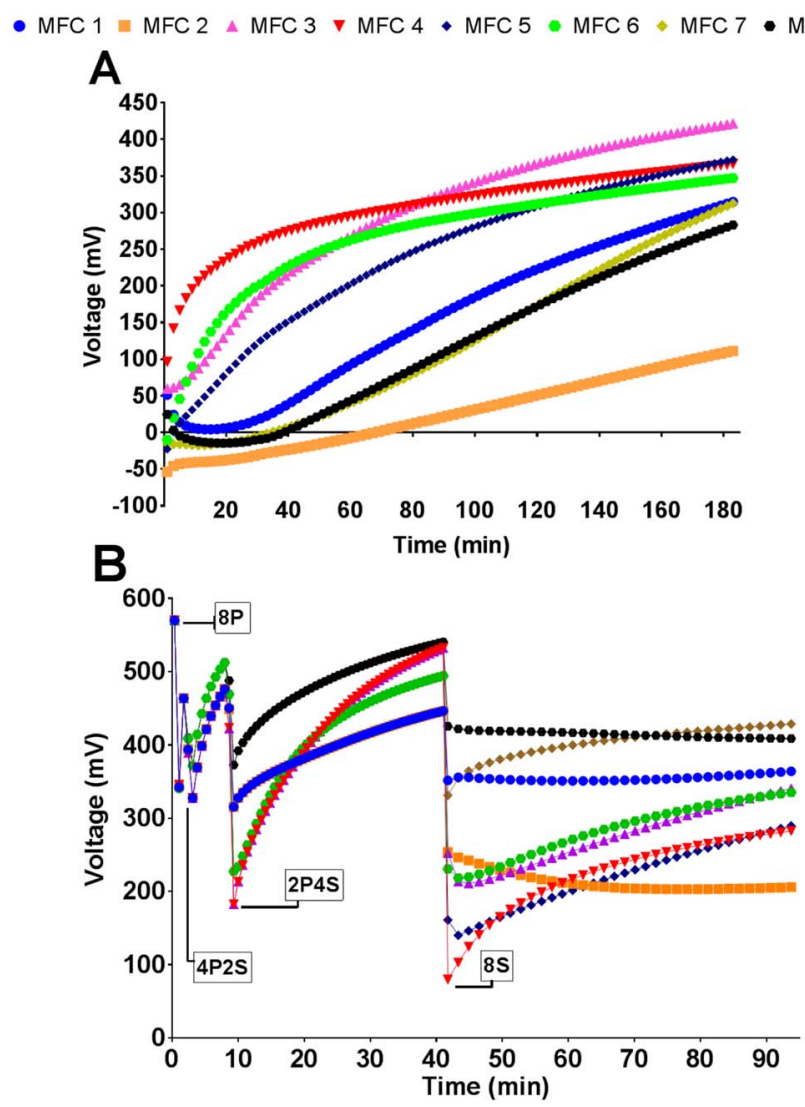

Figure 5. Individual MFC voltages whilst charging a $1 \mathrm{~F}$ super-capacitor to 3 $\mathrm{V}$ (A) with a fixed in-series and (B) with the variable reconfiguration PMS.

MFCs. ${ }^{18}$ In addition, the MFC that showed the lowest voltage value during charging was MFC 4, which indicated that cell reversals in a stack could even affect the best performing units (as with standard batteries).

Charging of the super-capacitor using the PMS from 0 to $0.5 \mathrm{~V}$ started with the $8 \mathrm{P}$ so as to maximize the current flow from the stack into the empty super-capacitor. The configuration automatically switched to 4P2S and continued charging until $1 \mathrm{~V}$. Following this, the system switched to $2 \mathrm{P} 4 \mathrm{~S}$, which resulted in the voltage reaching $2 \mathrm{~V}$. From that point all MFCs were connected in-series and left charging until $3 \mathrm{~V}$. Voltage readings (Fig. 5B) showed that none of the MFCs reversed as was the case for the fixed series configuration. The gradual switching from parallel to series elements established a lower overall $R_{\text {int }}$ in the stack and seemed to prevent cell reversal within the critical range of 0 to $1.4 \mathrm{~V}$. This suggested that the stack was prone to reversal but the presence of parallel elements prevented this by maintaining balance.

Optimising power transfer.-As with the manual variable reconfiguration previously reported to halve charging times by achieving higher energy transfer, ${ }^{23}$ in a similar manner, the automated variable switching improved power transfer from the stack during the charging process. Whilst MFCs being operated under the dynamic switching mode, the charging lasted $93 \pm 3$ min, which was $50 \%$ less than the time required under the fixed in-series formation $(184 \pm 3 \mathrm{~min})$. The improvement in charging times could be correlated with the 2-fold increased average power produced from the dynamic switching mode $(770 \mu \mathrm{W})$ compared to the fixed mode $(374 \mu \mathrm{W})$, in the same period of time (Fig. 6).

Feasibility of a self-powered PMS circuit with automated switching.-It is often the fact that an external voltage supply is required for either kick-starting or continuous operation of the energy

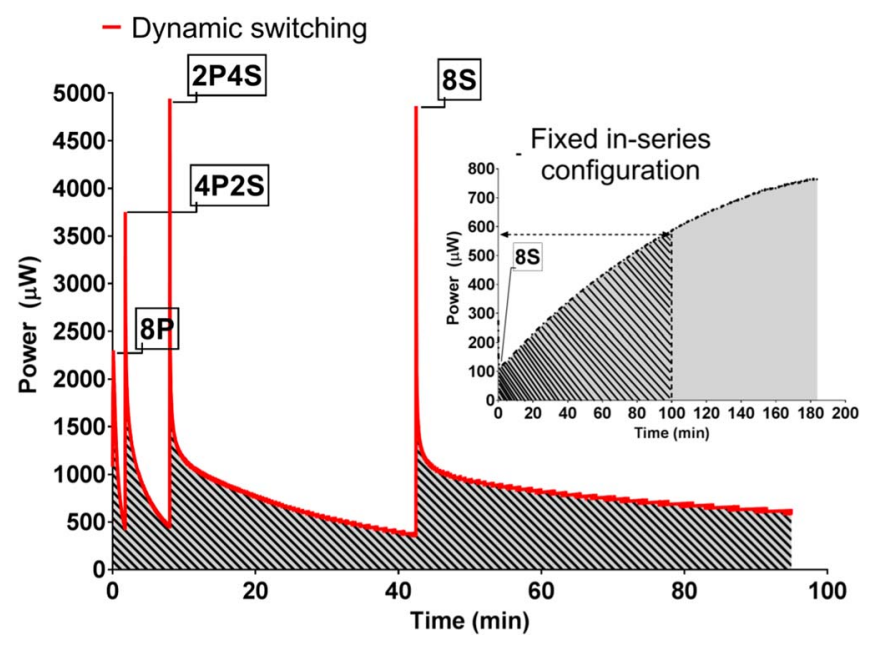

Figure 6. Power levels during charging from dynamic mode and, (inset) fixed mode. Filled areas indicate the same charging time.

harvester. Even though the auxiliary power supply ensures robust operation and longevity of the PMS, it is far from being energy selfsufficient. To date, many studies have put effort into eliminating the provision of external energy with either minimising the initial jumpstart voltage $^{33}$ or completely removing the need for one, resulting to pure energy autonomous harvesters. ${ }^{34-38}$

Based on previous theoretical projections, ${ }^{23}$ a novel PMS for automated switching was built (see supplementary material, Fig. S2) and tested on the 8-MFC stack. The external power supply was replaced with a small $6.7 \mathrm{mF}$ capacitor that harvested sufficient energy to run continuously the microcontroller for switching and voltage monitoring. However according to previous studies describing the development of MPPT active harvesters, it was deemed best to substitute all latching relays with transistors; $;{ }^{39,40}$ metal-oxide-semiconductor-fieldeffect-transistors (MOSFET) that consumed 1000-times less energy compared to a latching relay $(\sim 30 \mu \mathrm{J}$ each).

Preliminary results showed that after running continuously for a period of 18 hours, the PMS managed to perform fourteen complete charging/discharging cycles within this period (Fig. 7A). The presented time interval shown in the results is indicative of the time that is required for a MFC to run without the addition of fresh substrate. This suggested that every cycle required an average of $80( \pm 2)$ minutes, which is $18 \%$ faster than the automated switching technique reported above. The voltage on the start-up capacitor confirmed the smooth operation of the auxiliary capacitor (Fig. 7B). On top of that, logging of voltage in individual MFCs showed that the system prevented cell reversal even though at the beginning of each cycle the stack was configured in-series charging the auxiliary capacitor.

\section{Conclusions and Future Work}

Differences in $\mathrm{R}_{\text {int }}$ can lead to cell reversal in stacked MFCs when a low external resistance is applied. MFCs with the highest $\mathrm{R}_{\text {int }}$ are expected to go into reversal; however, results show that reversed MFCs are likely to affect the better performing units. This propagation effect cannot yet be easily predicted, but it is considered to be a function of $R_{\text {int }}$ combined with position in the stack that hinder rates of reaction in an anode, which is connected to the cathode of a reversed MFC. Variable switching is shown to maximize the transfer of the generated charge from the MFC stack into the storage device - in this instance a super-capacitor - by gradually substituting parallel elements for series within the stack. This has an additional positive effect on the $R_{\text {int }}$ which is reduced thus allowing for faster current flow by maintaining a potential disparity between the stack and the super-capacitor. Over and above that, it allowed for the development 

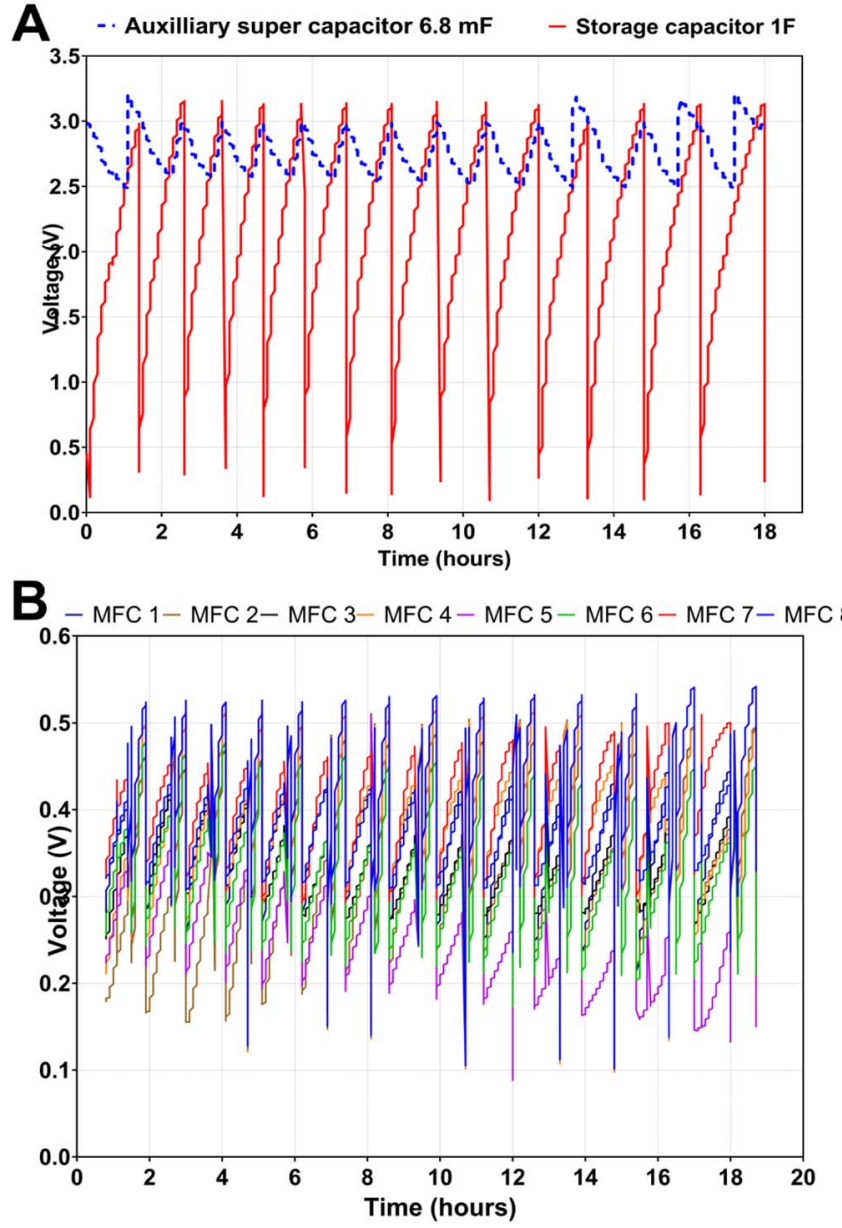

Figure 7. (A) Charging/discharging of a $1 \mathrm{~F}$ supercap from 0 to $3 \mathrm{~V}$ (red line) and simultaneous operation of the auxiliary capacitor whilst running the PMS (black line). (B) Voltage monitoring of all 8 MFC units in the stack during the 14 cycles of operation without any cell reversals.

of a prototype MFC-powered PMS capable of achieving efficiencies higher than 90\%; avoiding any capacitor-to-capacitor losses with enhanced fail-safe performance for continuous energy harvesting with the sole use of commercially available electronics without any voltage boosting components and external power supply.

\section{Acknowledgments}

This work is funded by the Engineering and Physical Sciences Research Council (EPSRC) UK, grant no. EP/H019480/1, Super- Gen Biological Fuel Cells Consortium. Special thanks to Dr. Jonathan Winfield for his valuable insight and input.

\section{References}

1. P. Aelterman, K. Rabaey, H. T. Pham, N. Boon, and W. Verstraete, Environ. Sci. Technol., 40, 3388 (2006).

2. I. Ieropoulos, J. Greenman, C. Melhuish, and I. Horsfield, Proc. Alife XII Conf., 733 (2010).

3. M. Rahimnejad, A. A. Ghoreyshi, G. D. Najafpour, H. Younesi, and M. Shakeri, Int. J. Hydrogen Energy, 37, 5992 (2012).

4. Z. Li, L. Yao, L. Kong, and H. Liu, Bioresour. Technol., 99, 1650 (2008).

5. J. Choi and Y. Ahn, J. Environ. Manage., 130, 146 (2013).

6. P. Ledezma, J. Greenman, and I. Ieropoulos, Bioresour. Technol., 134, 158 (2013).

7. H.-S. Lee, W. F. J. Vermaas, and B. E. Rittmann, Trends Biotechnol., 28, 262 (2010)

8. D. Jiang et al., Int. J. Hydrogen Energy, 36, 876 (2011).

9. J. An and H.-S. Lee, RSC Adv., 3, 14021 (2013).

10. H.-S. Lee and B. E. Rittmann, Int. J. Hydrogen Energy, 35, 920 (2010).

11. H.-S. Lee and B. E. Rittmann, Environ. Sci. Technol., 44, 948 (2010).

12. I. Ieropoulos, J. Greenman, and C. Melhuish, Int. J. Energy Res., 32, 1228 (2008)

13. L. Zhuang et al., Bioresour. Technol., 106, 82 (2012).

14. S.-E. Oh and B. E. Logan, J. Power Sources, 167, 11 (2007).

15. I. Ieropoulos, J. Greenman, and C. Melhuish, Bioelectrochemistry, 78, 44 (2010).

16. J. An and H.-S. Lee, ChemSusChem, 7, 1689 (2014).

17. H. Wang, J. Park, and Z. J. Ren, Environ. Sci. Technol., 19, 3267 (2015).

18. Y. Zhang and I. Angelidaki, Biosens. Bioelectron., 35, 265 (2012).

19. J. An, B. Kim, I. S. Chang, and H.-S. Lee, J. Power Sources, 278, 534 (2015),

20. H. C. Boghani et al., J. Power Sources, 269, 363 (2014).

21. Y. Kim, M. C. Hatzell, A. J. Hutchinson, and B. E. Logan, Energy Environ. Sci., 4, 4662 (2011).

22. R. P. Pinto, B. Srinivasan, S. R. Guiot, and B. Tartakovsky, Water Res., 45, 1571 (2011).

23. G. Papaharalabos et al., J. Power Sources, 272, 34 (2014).

24. C. Santoro et al., Bioresour. Technol., 163C, 54 (2014).

25. G. Papaharalabos et al., Int. J. Hydrogen Energy, 38, 11552 (2013).

26. P. Ledezma et al., Sustain. Energy Technol. Assessments, 5, 1 (2014).

27. A. Dekker, A. Ter Heijne, M. Saakes, H. V. M. Hamelers, and C. J. N. Buisman, Environ. Sci. Technol., 43, 9038 (2009).

28. C. I. Torres et al., Environ. Sci. Technol., 43, 9519 (2009).

29. P. Aelterman, S. Freguia, J. Keller, W. Verstraete, and K. Rabaey, Appl. Microbiol. Biotechnol., 78, 409 (2008).

30. J. Wei, P. Liang, X. Cao, and X. Huang, Environ. Sci. Technol., 44, 3187 (2010)

31. McKissock, B. Loyselle, P. Vogel, and Elisa, Guidelines on Lithium ion Battery Use in Space, p. 46, NASA Glenn Research Center, Cleveland, Ohio, (2009).

32. V. Kiran and B. Gaur, Rev. Chem. Eng., 29, 189 (2013).

33. P. K. Wu, J. C. Biffinger, L. A. Fitzgerald, and B. R. Ringeisen, Process Biochem., 47, 1620 (2012)

34. C. Erbay, S. Carreon-Bautista, E. Sanchez-Sinencio, and A. Han, Environ. Sci. Technol., 48, 13992 (2014)

35. S. Adami et al., Int. Conf. Electron. Circuits, Syst., 398 (2011).

36. X. Zhang et al., IEEE Trans. Power Electron., 30, 2041 (2015)

37. N. Degrenne et al., Proc. 2011 14th Eur. Conf. Power Electron. Appl., 1 (2011).

38. N. Degrenne et al, 889 (2011).

39. M. Alaraj, Z. J. Ren, and J.-D. Park, J. Power Sources, 247, 636 (2014).

40. J.-D. Park and Z. Ren, J. Power Sources, 208, 322 (2012). 